\title{
ADREAM: Energy Consumption Optimisation through Dynamic Energetic Simulations for an Intelligent Management of Energy
}

Ilias PAPAS, Carlos GARCÍA RODRÍGUEZ, Bruno ESTIBALS, Christelle ECREPONT, Corinne ALONSO

\author{
LAAS-CNRS \\ 7, Avenue du colonel Roche \\ 31077 Toulouse Cedex 4, France \\ E-mail : ipapas@laas.fr
}

\begin{abstract}
The ADREAM building consists of an innovative architectural structure which integrates 6500 sensors for the purposes of optimized systems and energy surveillance. Amid growing needs for energy optimization research and new technological developments in renewable energies, the ADREAM project stands as a prototype example for creating a multidisciplinary platform that allows the rapid progress of the Energy Networks and Smart Grid domains. A description of the ADREAM project is presented along with the energetic and control systems installed. The methodology for the development and calibration of the building's the rmal model and dynamic simulation is also highlighted. The simulations are exploited for the purpose of a the rmal behavior, comfort, and energy consumption analysis. The results obtained by the applied parame tric variations we re used for the proposition of a building renovation investment. The energy optimization goal is enhance d by the development of an ARX model for the prediction and control of energy consumptions, and a Simulink model for the global simulation of all the energetic systems.

Keywords - Building Simulation, Energy Optimization, Pleiades + Comfie, Simulation methodology, Model Calibration, ARX Model, Simulink
\end{abstract}

\section{INTRODUCTION}

Energy management and optimization is a growing issue for our society. To counter any associated problems, we must rely on the conception of New Generation Energy Networks, which need to be reactive and adaptive. Advanced Energy Networks must possess validated performance and functioning properties in terms of production, consumption and command. They need to accept multiple heterogeneous sources in terms of technology, availability and power, responding adequately and accurately to rapid, non-anticipated, variations by the user. It is these needs that gave rise to the concept of a Smart Grid, an energy network that not only deals with energy transportation, but also with telecommunication, measurement (sensors) and advanced management [16].

\section{The ADREAM scientific project}

\section{A. Principles and objectives}

The ADREAM project (French acronym for Embedded Reconfigurable Dynamic Autonomous and Mobile Architectures) is a research program focused on Smart Grids, as well as on Ambient Physical Cyber Systems. Effectively, the domains of integrated systems, robotics, and networks, have progressed considerably during recent years. That is, emerging systems who are strongly interacting with their environment and with dynamic constrains. These systems are heterogeneous, integrated, and mobile, while possessing detection and action functions. Thus, they must respond to operational constraints in terms of time and energy by being adaptive and resilient.

The scientific objectives associated with these techniques are based on all aspects linked to the concept and evaluation of New Generation Energy Networks. The related domains include power electronics, data processing, security functioning, and automation. The resolution of the associated challenges demands:

- The understanding of the different behaviors of connected parts in an electrical network, such as photovoltaic panels and inverters, through complete model elaboration and analysis.

- The implementation of a complex data processing system, necessary for the global network command and for the guarantee of performance quality and functional assurance.

- The evaluation and validation of the global energy network behavior, particularly considering the passage of the project prototype to an infrastructure level.

- A modeling approach to energy management and optimization for the totality of the systems, integrating all the entities of production and consumption, by deploying the extensive network of intelligent sensors and regulators.

The last point is the one we aim to elaborate throughout this paper. This project provides an overview of two different modeling and simulation methods which aim to propose applicable solutions for the energy consumption optimization of ADREAM.

The first method involves the calibration of a Dynamic Thermal Simulation for the purpose of analyzing the thermal behavior of the building and reducing its electrical consumption. The second method describes the ARX (Auto Regressive with eXternal inputs) model which is exploited with the objective of exploring optimized control strategies. The third part of this project lays out the initial development phase of an inclusive and validated model (MatLab and Simulink) which represents the totality of the ADREAM energy network. This method aims to provide an optimal configuration of the systems' parameters, which can serve as a prototype example for a sustainable building. 


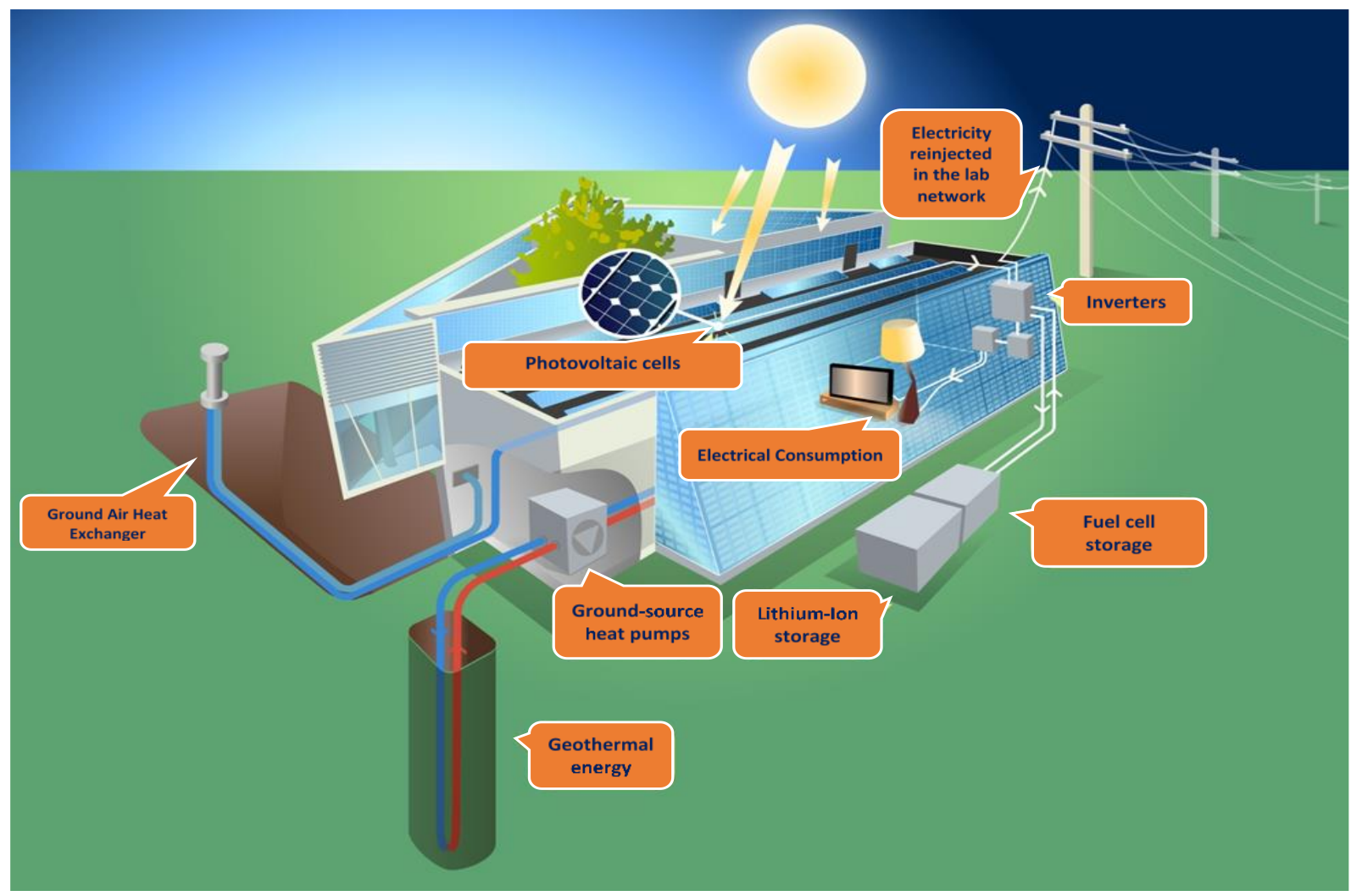

Figure 1: Energy systems present in ADREAM

\section{B. Energetic Systems}

The focus of this study concerns the transfer of energy within the ADREAM building considering the heating, the air conditioning, the lighting, and the various electronic devices. ADREAM is connected to an electrical grid which benefits from a total of $100 \mathrm{kWc}$ of photovoltaic energy. In addition, it involves the use of geothermal energy through the installation of three ground source heat pumps $(135 \mathrm{~kW})$. The hygienic ventilation system is also linked to a ground heat exchanger to minimize the heating/cooling energy needs of the air. The notion of the Smart Grid is examined extensively through the ADREAM research program as the electrical energy surplus from the photovoltaic production, combined with the optimized consumption of high performance HVAC (Heating, Ventilation, and Air Conditioning) systems, can be transported to the rest of the buildings composing the LAAS-CNRS laboratory. The principal objective of the ADREAM project was to give rise to a building of optimized energy consumption and production, while achieving periodical states of positive energy, without compromising user comfort. Figure 1 shows the interconnection of the various energy systems installed in the building.

\section{Dimensioning and Surveillance}

ADREAM is an instrumented building which is connected to a control and supervision system. Coupled with a database, the system allows the registration of measurements for reporting and analysis purposes. The control and supervision is carried out through the software PCVue, developed by ARC Informatique [15], adapted to the technical specifications of the building. This system is tied to 6500 integrated sensors and various controllers (WAGO, TAC) which regulate the whole installation. The registration of the data takes place periodically with a frequency varying from 1 to 5 minutes, according to the different setup of each sensor. This information is then measured, posted, and registered by the PCVue software. The daily number of data points registered in the database can reach 500000 . The objective of this management system is, on one hand to assure the automatic functioning of the building (thermal and lighting regulation with the possibility of minor variations by the occupants according to their comfort perception), and on the other hand to supervise in real time the operation of the various interconnected equipment for the purpose of a detailed energetic analysis and optimization. The PCVue program allows the surveillance of the intelligent lighting system, the functioning and control of the HVAC systems, and the supervision of the photovoltaic production along with the electrical consumption.

\section{Dynamic Thermal Simulation}

\section{A. Motivation}

A Dynamic Thermal Simulation (DTS) serves as a computer tool that allows the thermal study and energetic assessment of a building from multiple perspectives (temperature profiles, energy consumption, comfort). The interest of this project was 
to model with high precision the particular architecture of ADREAM's structure, along with its thermal properties and the technical characteristics of the systems installed. The challenge of this task lied in the complex nature and interaction of the various HVAC systems, as well as in the polyvalent usage of the building (volatile occupation and utilization of electronic equipment). Once the initial phase of the thermal modeling was completed, the calibration process of the resulting model was accomplished through the extensive exploitation of the data registered by the numerous integrated sensors. As suggested by the definition of a DTS, this project aims to analyze the existing conditions of the building in terms of its thermal behavior and energy consumption, as well as to predict the corresponding results of a parametric variation study. The purpose of a parametric variation, according to possible realistic installation and regulation upgrades, is to identify the potential problems related to the existing configuration and to provide the framework of an improvement strategy. That is, by simulating multiple scenarios of solutions, the main objective of this study is the optimization of energy consumption and management through ameliorations of the existing installation and on the regulation of the HVAC systems functioning.

\section{B. Software}

The initial modeling phase of the building ADREAM was carried out by the software Pleiades + Comfie $(\mathrm{P}+\mathrm{C})[1] . \mathrm{P}+\mathrm{C}$ is a widely used thermal simulation program developed at the Ecole des Mines in Paris and supplied by the company Izuba. As indicated by Peuportier [2], $\mathrm{P}+\mathrm{C}$ can be considered as a precise simulation tool for the generation of temperature evolution and energetic needs profiles, as well as for the study of their sensibility to main thermal parameters. The choice of the software for the purpose of this project was based on: a) the consistent development of the software through frequent updates which involve additional parametrization options, b) experience of use, and c) a "user-friendly" interface. The main entry parameters involved in the modeling process of ADREAM with the $\mathrm{P}+\mathrm{C}$ program employed the thermal characteristics of its structure, the scenarios of usage, the systems characteristics and a complete weather file. This file was based on the data extracted by the meteorological station installed on the roof of the building. The key parameters, for which an extensive analysis was needed in order to be estimated as precisely as possible, consisted of: a) the presence of a very wide range of electronic devices for the purpose of a diverse research program expanding from robotics to energy production optimization, b) the significant variation of the occupation levels from a weekly and yearly point of view, and c) the uncertainty of the users' actions on the regulation of their offices (temperature and ventilation set points). Even though $\mathrm{P}+\mathrm{C}$ does not have a Model Predictive Control (MPC) capacity, it allows the possibility of further model refinement on a weekly and yearly basis for certain scenarios which depend on highly variable parameters (temperature set points, ventilation air flow, solar protection, internal heat gains based on electronic device usage and occupation). Once the input of the fixed parameters was completed and the first simulations were launched, the variable parameters were exploited for the purpose of a reasonable and accurate calibration process. The calibration phase was mainly based on the identification of errors in the model that depended highly on the variable parameters mentioned above. Thus, their extensive analysis was performed with the help of the data registered by the various integrated sensors in accordance with several hypotheses outlined further below.

\section{Model algorithm}

The calculation method of the COMFIE engine is based on a thermo-electrical analogy where:

Electric current $[\vec{\jmath}] \leftrightarrow$ Thermal flux $[\vec{\varphi}]$

Electric potential $[\Delta \mathrm{V}] \leftrightarrow$ Temperature difference $[\Delta \mathrm{T}]$

Electric conductivity $\left[\rho^{-1}\right] \leftrightarrow$ Thermal conductivity $[\lambda]$

Figures 2 and 3 represent this analogy by the equivalent thermal and electrical model respectively. Figure 2 shows that the temperatures of the different layers composing the wall can be reduced to single values corresponding to the various nodes $(1,2,3)$. The thermal flux traverses the wall according to the 1dimensional thermal conductivity of the material as given by equation 1:

$$
\lambda=\frac{\dot{Q} \cdot L}{A \cdot \Delta T}[\mathrm{~W} / \mathrm{mK}]
$$

Where:

Q: heat flux [W],

$\mathrm{L}$ : thickness of the material [m],

A: the surface area $\left[\mathrm{m}^{2}\right]$,

$\Delta \mathrm{T}$ : temperature difference $[\mathrm{K}]$.
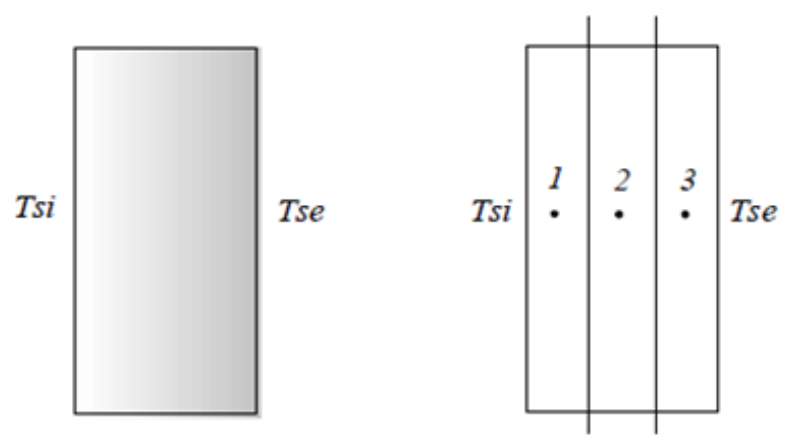

Figure 2: Wall discretization ( $\Delta T=T s i-T s e)[10]$

As Boyer et al [10] highlight, according to the discretization assumption for a monodimensional wall, the nodes correspond to isothermal lines and they can be represented in an electric

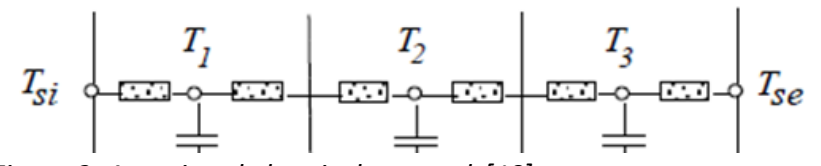

Figure 3: Associated electrical network [10] 
configuration as equipotentials. Figure 3 demonstrates the equivalent electric network representation where the nodes are linked through blocks of resistance $\left(R_{T H}=f(\lambda)\right)$. The role of the capacitor connected to each node is to store thermal energy in function with its thermal mass.

As Peuportier [3] explains, the COMFIE engine is a software which calculates the thermal performance of a multi-zonal building according to a mathematical model which is based on a nodal analysis, allowing a significant reduction of the calculation time. The model is initially applied on a single zone, independent of others, in accordance with the heat transfer equations established for every grid node of the zone under examination. According to Boyer et al. [10], the thermal state of the zone is determined by a continuous field of temperatures, concerning all points within the physical limits of the building. Figure 4 shows the thermal discretization of the building, as reduced by the thermal model after important simplifications.
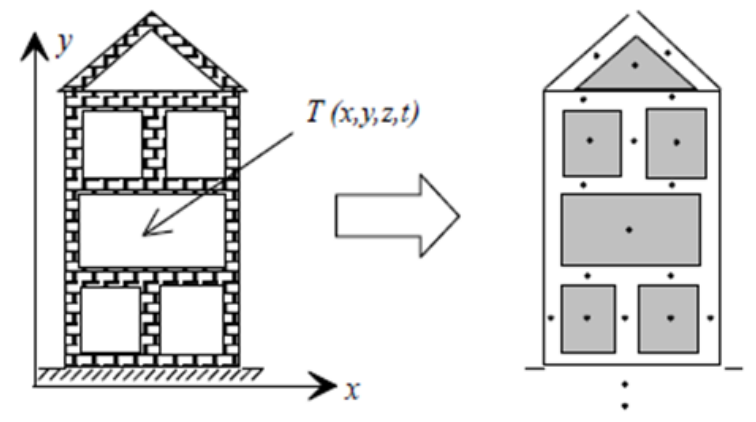

Figure 4: Thermal Discretization [10]

Therefore, the COMFIE engine decomposes the project in meshes which represent different portions of a wall, and whose temperature values were calculated according to thermal equations through a system of matrices. The system of equations 2 [3] presents the simplified mathematical model of the COMFIE calculation process.

$$
\begin{gathered}
C \cdot \dot{T}=A \cdot T+E \cdot T \\
Y=J \cdot T+G \cdot U
\end{gathered}
$$

Where:

T: Discretized field of mesh temperatures

$\mathrm{U}$ : Thermal flux vectors

C: Diagonal matrix of thermal capacities

A: Thermal coefficient matrix between mesh points

E: Thermal coefficient matrix between mesh points and flux values

Y: Observation vector (system evolution vector in terms of temperature or flux)

$\mathrm{J}$ : Observation matrix (sensibility of measures)

G: Matrix of direct transmission (instant action of fluxes)

The differential equation corresponding to the matrix forms the state equation through which the closed system evolves, taking into account discretization [10]. The differential form of the matrix, corresponding to the thermal balance equation for the various nodes calculated is given by the system of equations 3 [10].

$$
\begin{gathered}
C_{S I} \frac{d T_{S I}}{d t}=h_{C I}\left(T_{A I}-T_{S I}\right)+h_{R I}\left(T_{R M}-T_{S I}\right)+K\left(T_{S E}-\right. \\
\left.T_{S I}\right)+\varphi_{S W I}(3 \boldsymbol{a}) \\
C_{S E} \frac{d T_{S E}}{d t}=h_{C E}\left(T_{A E}-T_{S E}\right)+h_{R E}\left(T_{S K Y}-T_{S E}\right)+K\left(T_{S I}-\right. \\
\left.T_{S E}\right)+\varphi_{S W E}(\mathbf{3 b}) \\
C_{A I} \frac{d T_{A I}}{d t}=\sum_{j=1}^{N w} h_{C I}\left(T_{A I}-T_{S I}(j)\right)+c \dot{Q}\left(T_{A E}-T_{A I}\right)(\mathbf{3 c}) \\
0=\sum_{j=1}^{N w} h_{R I} A_{J}\left(T_{S I}(j)-T_{R M}\right)(\mathbf{3 d})
\end{gathered}
$$

Where:

CSI: Thermal capacity of interior surface

$\mathrm{C}_{\mathrm{SE}}$ : Thermal capacity of exterior surface

$\mathrm{C}_{\mathrm{AI}}$ : Thermal capacity of interior space within boundary condition

c: Specific heat capacity

TSI: Temperature of interior wall layer

$\mathrm{T}_{\mathrm{SE}}$ : Temperature of exterior wall layer

$\mathrm{h}_{\mathrm{CI}}$ : Interior linear exchange coefficient due to convection

$\mathrm{h}_{\mathrm{CE}}$ : Exterior linear exchange coefficient due to convection

$\mathrm{T}_{\mathrm{AI}}$ : Interior air temperature

$\mathrm{T}_{\mathrm{AE}}$ : Exterior air temperature

$\mathrm{h}_{\mathrm{RI}}$ : Interior exchange coefficient due to radiation

$h_{R E}$ : Exterior exchange coefficient due to radiation

$\mathrm{T}_{\mathrm{RM}}$ : Mean Radiant Temperature

$\mathrm{K}$ : Thermal conductivity

$\mathrm{N}_{\mathrm{w}}$ : Number of walls of the envelope

$\mathrm{A}_{\mathrm{j}}$ : Surface area

$\dot{Q}$ : Mass flow rate

$\varphi$ swi: Interior radiation flux density

$\varphi$ swe: Exterior radiation flux density

As explained by Boyer et al. [10], equations $3 \mathrm{a}$ and $3 \mathrm{~b}$ correspond to the thermal balance of the interior and exterior surface nodes, equation $3 \mathrm{c}$ to the thermo-convective balance of the interior temperature, taking into account airflow, and equation $3 \mathrm{~d}$ to the radiative balance of the Mean Radiant Temperature (MRT). The MRT describes the uniform interior temperature of a system arising from the net exchange of radiant energy between two or more objects, according to their ability to emit and absorb heat.

Thus, the simplified matrix form corresponding to the above system of differential equations for a multi-zone building can be summarized in the form of equation 4 [10].

$$
\left[\begin{array}{ll}
\mathrm{Cl}_{1} & \\
& \\
& \mathrm{C}_{2}
\end{array}\right]\left[\begin{array}{l}
\dot{\mathrm{T}}_{1} \\
\dot{\mathrm{T}}_{2}
\end{array}\right]=\left[\begin{array}{ll}
\mathrm{A}_{1} & \times \times \\
\mathrm{x} & \mathrm{A}_{2} \\
\mathrm{x} &
\end{array}\right]\left[\begin{array}{c}
\mathrm{T}_{1} \\
\mathrm{~T}_{2}
\end{array}\right]+\left[\begin{array}{c}
\mathrm{B}_{1} \\
\mathrm{~B}_{2}
\end{array}\right]
$$


This matrix combines the differential equations for each zone as described above, where $\mathrm{C}$ represents the thermal capacities, $\mathrm{A}$ the thermal coefficients, and B the thermal fluxes.

\section{Methodology}

The modeling methodology of the building ADREAM depended on the available information supplied by the companies involved in its construction (plans, materials, HVAC systems technical information) and on the analysis of the data registered by the integrated sensors. Initially, the geometry of the building was designed with the use of the Alcyone interface, which allows a 3D representation of the structure for thorough visualization and representation of architectural problems. Once the form of the building was depicted, the thermal characteristics of each wall, floor, and window component were applied. Through this interface, it was also possible to assign the corresponding thermal bridges for every wall-wall, wall-floor and wall-window link. The final stage of the geometry design process involved the division of the building into thermal zones. For maximum precision and analysis potential, 40 thermal zones were applied to the totality of the building (out of 45 existing rooms/offices).

The finalization of the design phase was accomplished with the insertion of a weather file based on the data of the meteorological station installed on the roof of the building (sensors of temperature, global irradiation, relative humidity, wind speed, wind orientation). The weather file allowed a natural lighting calculation on the Alcyone interface which facilitated the modeling of the artificial lighting needs of the building. This process was highly significant as it contributed to the precise modeling of the existing intelligent lighting management and to the accurate calculation of the electrical consumption based on the use of the interior lamps. Figure 5 represents the 3D model of ADREAM in the Alcyone interface.

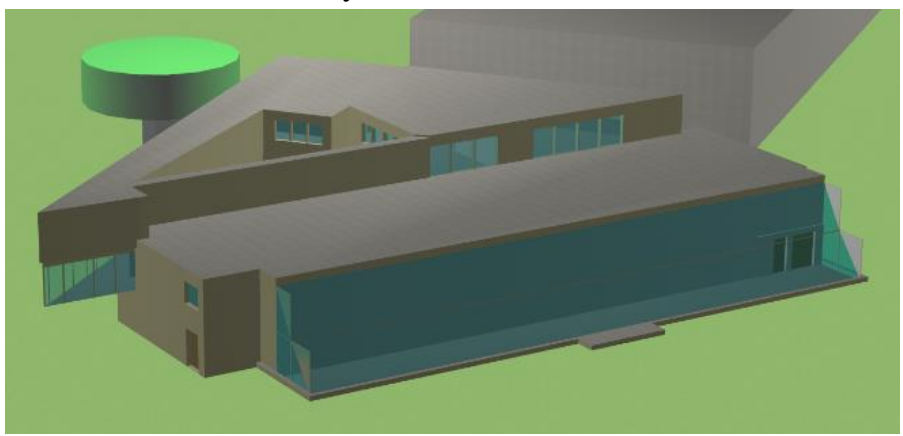

Figure 5: 3D model of ADREAM in the Alcyone environment

The next step of this study involved the exporting of the project file from Alcyone to the Pleiades environment, where the refined parametrization process took place. The Pleiades interface allowed the insertion of all the usage scenarios and the technical characteristics of the HVAC systems. Once all the necessary information was entered, multiple simulations were run for the purposes of model calibration and results analysis.
Figure 6 represents the methodology of the whole modeling process.

Remark: The processes of "Error Check" and "Error Fix" define respectively the identification of errors in the initial weather data sheets (measurement gaps, false registrations, etc.), and the corresponding procedure of correcting the missing or false values was completed with Excel or MatLab.

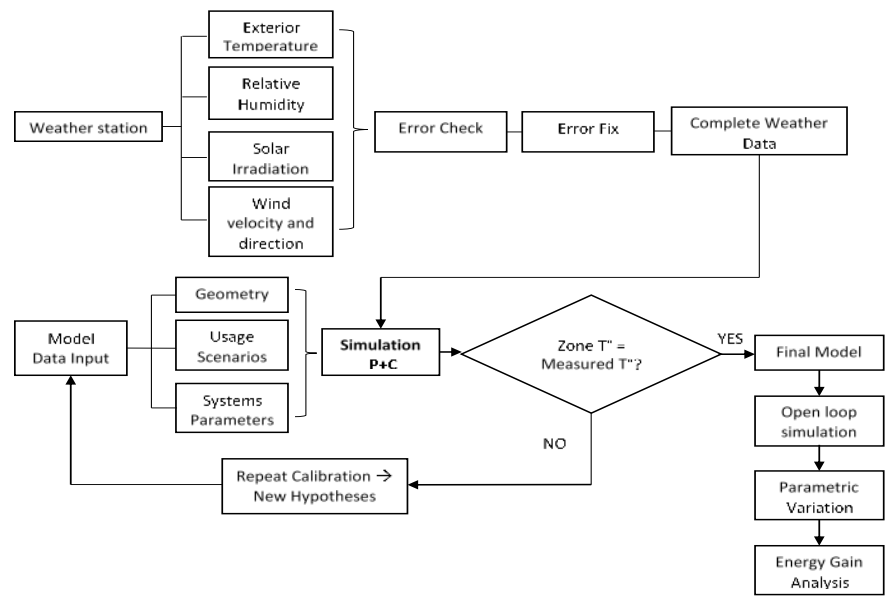

Figure 6: Modeling methodology for the building ADREAM

\section{E. Dimensioning and Model Calibration}

After the entry of all the parameters in the $\mathrm{P}+\mathrm{C}$ software and the run of the first simulations, it was important to compare the results with real data as registered by the integrated sensors. This comparison served as a model calibration process. Prior to this phase, an extensive analysis and treatment of the registered data was carried out. Data collection and analysis was facilitated with the use of MatLab, through which it was possible to adjust: a) the format, and b) the time-step of temperature measurements to 1-hour intervals, matching the time-step of the $\mathrm{P}+\mathrm{C}$ simulation results. Once the temperature data for all the zones was produced in the right format, it was possible to compare it with the results of the simulation on a short-term (2-3 weeks) and long-term (full year) basis.

The calibration process was completed through the calculation of two statistical indicators, as proposed by the ASHRAE Guideline 14-2002 [7]. Model calibration between simulated and measured data can be estimated with the use of the Normalized Mean Bias Error (NMBE) and the Coefficient of Variation of Root Square Mean Error CV(RMSE). These indicators are written in the form of the equations 6 and 7 respectively.

$$
\operatorname{NMBE}(\%)=\frac{\sum_{i=1}^{n}(\text { Tsim }- \text { Tmes })}{n-1} \cdot \frac{1}{\overline{\text { Tmes }}} \cdot 100
$$

Where:

Tsim: Simulated temperature value

Tmes: Measured temperature value

$\overline{\text { Tmes: }}$ Arithmetic mean of the sample of $\mathrm{n}$ measurements $\mathrm{n}$ : number of data points (temperature values) 
As described by Nguyen [8], a positive value of NMBE indicates an over-estimate while a negative value shows an under-estimate by the model. An ideal NMBE should be around 0 .

$$
C V(R M S E)(\%)=\sqrt{\frac{\sum_{i=1}^{n}(\text { Tsim-Tmes })^{2}}{n-1}} \cdot \frac{1}{\frac{T_{\text {Tmes }}}{n-1}} \cdot 100
$$

Estimating model fitting with the use of CV(RMSE) demonstrates the differences in values between measured and simulated data. CV(RMSE) is always positive and an ideal value is close to 0 .

For our study, a NMBE lower than $1 \%$ and a CV(RMSE) less than $10 \%$ were considered as accurate indicators of a precise thermal model for the purpose of a parametric variation that aims to optimize energy management.

The $\mathrm{P}+\mathrm{C}$ model was calibrated after a series of validated estimations and hypotheses, which were based on in situ measurements and information extracted from a survey on the ADREAM's occupants. Table 1 shows the evolution of the statistical indicators (NMBE and CV(RMSE)) from the initial to the final simulation, while Figure 7 demonstrates the fit between measured data (T_REAL) and simulated data (T_INITIAL_SIMULATION and T_FINAL_SIMULATION).

Table 1: Statistical indicators for the initial and final simulations

\begin{tabular}{|l|c|c|}
\hline $\begin{array}{l}\text { Statistical } \\
\text { Indicator }\end{array}$ & $\begin{array}{l}\text { T_INITIAL } \\
\text { SIMULATION }\end{array}$ & $\begin{array}{l}\text { T_FINAL } \\
\text { SIMULATION }\end{array}$ \\
\hline NMBE & $4.57 \%$ & $0.48 \%$ \\
\hline CV(RMSE) & $5.51 \%$ & $2.84 \%$ \\
\hline
\end{tabular}

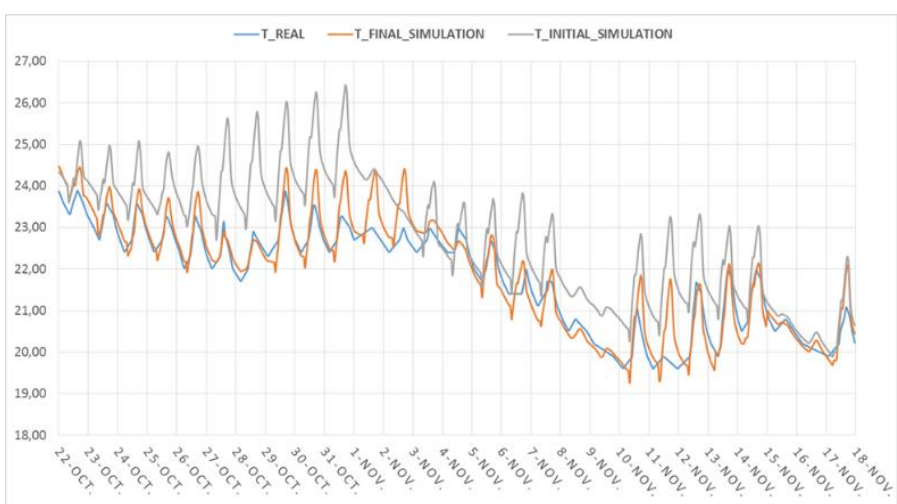

Figure 5: Model calibration for the period of October - November

\section{F. Complete Simulation Results}

The final step for carrying out a complete simulation including the building's thermal behavior analysis, as well as its electrical consumptions, involved the entry of all the HVAC systems' parameters. That is, in order to launch a complete simulation the required information concerned all the technical parameters of: a) the three heat pumps, b) the central AHU and the five individual AHU's, c) the ceiling fan coils, and d) the radiators. The technical parameters concern variables such as: the coefficient of performance, the power consumed by the ventilators, the length of the circuit, the functioning temperature set-point, etc. Once the corresponding parameters were entered in the $\mathrm{P}+\mathrm{C}$ interface and connected appropriately to the rest of the project, the complete simulation was initiated. The calibration process was repeated for the complete simulation in a similar way as for the base DTS. The most important adjustment concerned the heat pumps' coefficient of performance (COP), which was increased according to the real data values registered in the system and was slightly superior to the COP provided by the supplier. In addition, the theoretical air flow values given by the supplier of the AHU were corrected according to the measured values. Thus, the final results concerning the electrical consumption per source were compared to the measured values supplied by the laboratory and are presented in table 2 .

Table 2: Comparison between real and simulated electrical consumption by source

\begin{tabular}{|l|c|c|c|c|}
\hline \multicolumn{1}{|c|}{$\begin{array}{c}\text { Consumption } \\
\text { Source }\end{array}$} & \multicolumn{2}{|c|}{$\begin{array}{c}\text { Real } \\
\text { Consumptions } \\
\text { [MWh/an] }\end{array}$} & $\begin{array}{c}\text { Simulated } \\
\text { Consumptions } \\
\text { [MWh/an] }\end{array}$ & $\begin{array}{c}\text { Relative } \\
\text { Error [\%] }\end{array}$ \\
\hline Heat Pump 1 & 9,03 & 36,49 & 3,05 \\
\hline Heat Pump 2 & 16,71 & 35,41 & 17,55 & 1,35 \\
\hline Heat Pump 3 & 9,67 & 17,79 & 63,63 & 8,63 \\
\hline $\begin{array}{l}\text { Air Handling } \\
\text { Unit }\end{array}$ & 69,64 & 63,43 & 3,56 \\
\hline $\begin{array}{l}\text { Distribution } \\
\text { Pumps }\end{array}$ & 65,77 & 11,89 & 1,16 \\
\hline $\begin{array}{l}\text { Electronic } \\
\text { Equipment }\end{array}$ & 12,03 & 192,88 & 3,82 \\
\hline Lighting & 200,64 & & \\
\hline TOTAL & & & \\
\hline
\end{tabular}

\section{G. Electric consumption analysis}

The lack of the potential to switch off the functioning of the heating and cooling system according to comfortable interior temperature raises the issue of a more optimized energy usage. As observed in table 6, one of the highest sources of electric energy consumption corresponds to the constant functioning of the distribution pumps. The current pumps were installed according to the Thermal Regulation of 2005 (RT2005) and they are no longer allowed for new constructions or renovations. The main reason is the fact that they constantly work, consuming at all times $1 \mathrm{~kW}$ to $1.5 \mathrm{~kW}$ per pump ( 7 pumps in total). Thus, even during the periods when the heating and cooling needs of the building are lower, or minimal, the electric consumption remains the same as when the needs are maximal. This problem, combined with the conclusions of the open-loop simulation and the poor regulation (automatic change between winter/summer mode), can be addressed either through the installation of a frequency regulator or through the complete replacement of the pumps. The energy gain from this improvement strategy is analyzed in part $\mathrm{G}$. 


\section{H. Discussion of Proposed Improvements}

\section{Temperature set-point variation}

The first improvement scenario studied involved the variation of the temperature set-point. For the winter period, the set-point was decreased from $21^{\circ} \mathrm{C}$ to $20^{\circ} \mathrm{C}$ and finally to $19^{\circ} \mathrm{C}$. Similarly, for the summer period the set-point was increased from $23^{\circ} \mathrm{C}$ to $24^{\circ} \mathrm{C}$ and eventually to $25^{\circ} \mathrm{C}$. These variations aimed on reducing the heating and cooling needs for the totality of the building during the whole year, with the objective of minimizing the electrical consumption of the heat pumps. Thus, the simulated energy gain from these actions corresponded to values varying from $2 \%$ to $4 \%$. Considering the current performance of the heat pumps (COP that can reach a value of 7), this outcome was sensible. Moreover, according to the responses received through the survey, the comfort of a significant number of occupants would be compromised, as the set-points available on the individual thermostats are increased in the winter and decreased in the summer. Therefore, since this variation didn't produce a significant energy gain, a related action was considered unnecessary for application.

\section{Regulation/replacement of distribution pumps}

As discussed previously, a regulation or replacement of the distribution pumps from constant-flow to variable-flow can lead to significant energetic gains. This improvement scenario was simulated through $\mathrm{P}+\mathrm{C}$ by changing the parametrization of the ceiling fan coils and the AHU. Therefore, by replacing the network operation principle of the AHU and each fan coil from constant-flow to variable-flow, the corresponding energy gain was on the level of $20 \%$. This amount of energy gain for an already optimized building was considered significant, especially by taking into account ADREAM's capacity for energy production through the PV panels. Thus, by proposing the replacement of the distribution pumps with new pumps that have the potential to modulate the water flow according to heating and cooling needs, the ratio of energy use VS energy production can be further optimized.

\section{ARX Modeling}

For very complex systems and interactions, such as the ones corresponding to the building ADREAM, it is often useful to use the ARX modeling method [14]. This method provides the capacity to predict the data stemming from the production and consumption elements (heat pump water temperatures, power consumption, etc.) for the purpose of evaluating different control strategies.

The ARX method approximates the physical equations governing the interaction of the energetic systems by applying linear differential equations which associate a specific output to a finite number of past inputs and outputs. Equation 8 demonstrates the association of the different inputs and outputs using the ARX model.

$$
\begin{gathered}
A(t) y(t)=B(z) u(t-n k) \Rightarrow \\
a_{1} y(t-1)+\cdots+a_{n a} y(t-n a)= \\
b_{1} u(t-1)+\cdots+b_{n b} u(t-n k-n b+1)
\end{gathered}
$$

Where:

$y(t)$ : Current output

$\mathrm{y}(\mathrm{t}-\mathrm{k})$ : Past output

$\mathrm{u}(\mathrm{t}-\mathrm{k})$ : Input

As of now, prior to advancing to the rest of the systems, this method is applied on the functioning of the heat pumps with the aim of optimizing their control. For the estimation of the model, the data that corresponds to the heat pump variables is used. This information needs to expand over a long period of time so that the resulting equations are considered reliable. For the purpose of the heat pump modeling, the temperature of the water entering from the geothermal source and the water returning from the secondary circuit, along with the power of the compressor, are considered as inputs. The desired outputs correspond to the hot and cold water exiting the heat pump towards the secondary circuit. The results obtained from the prediction of the output temperatures, which consequently provide the equivalent power consumption are given in Figure 9 with various step predictions. The next step of this work requires the determination of the most optimal control of the output temperatures according to Figure 9.

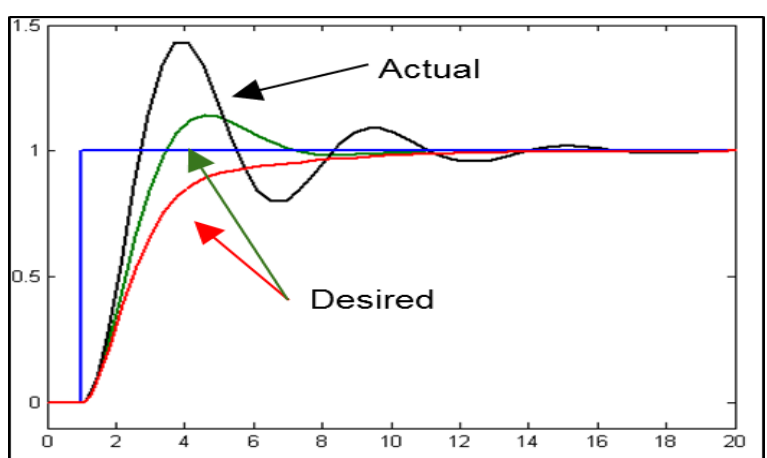

Figure 6: Control strategies explored for the optimization of the heat pump output temperatures

V. Conclusion and Future Work

A complete thermal model of the instrumented building ADREAM was created, calibrated and analyzed through the use of the Energy Simulation Software Pleiades + Comfie. The model was calibrated through the exploitation of data measured by the integrated sensors and registered by the surveillance software PCVue. The calibration process was validated through the use of statistical indicators which were improved to acceptable limits as the model was refined. 


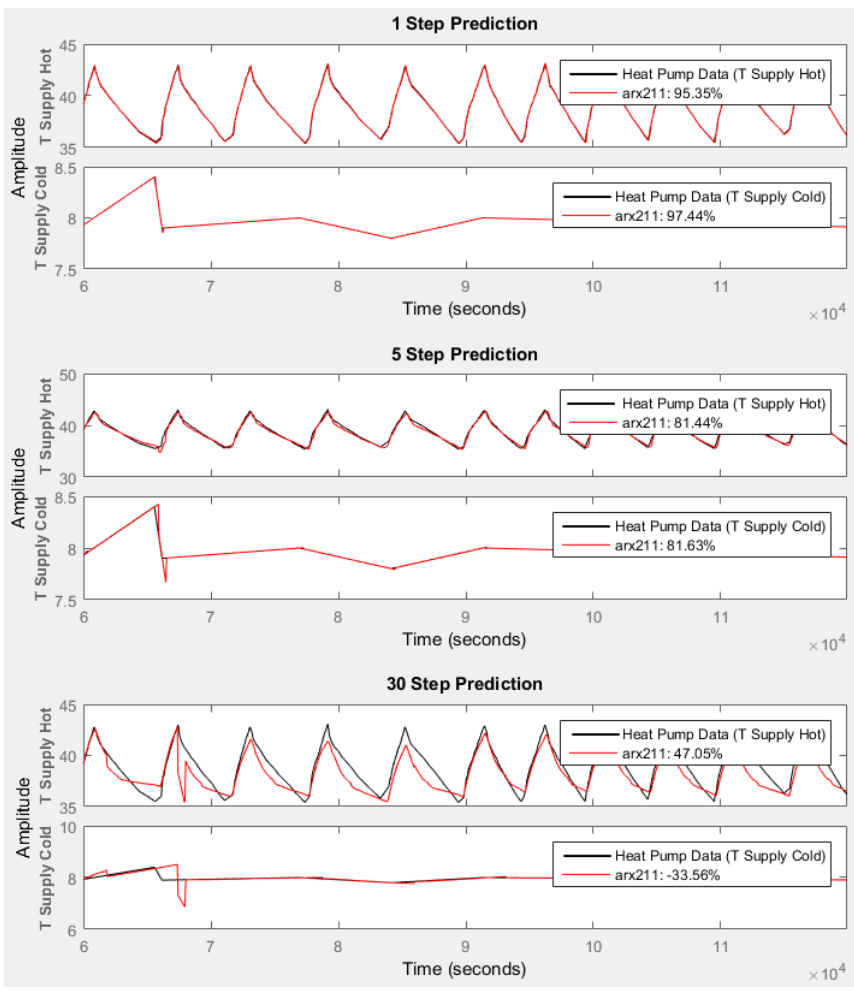

Figure 9: Prediction of Heat Pump Output Temperatures

A parametric variation procedure was produced for the purpose of installation and regulation improvements that aim to optimize energy consumption without compromising the comfort of the occupants. The results show that the variation of the temperature set points can lead to a maximum of $4 \%$ energy gain. However, a replacement of the circulation pumps from constant-flow to variable-flow ones, leads to a $20 \%$ energy gain.

This work served as an initial extensive thermal study of the instrumented building ADREAM and can serve as an example of a modeling methodology for buildings of complex architecture and usage through the exploitation of the $\mathrm{P}+\mathrm{C}$ software capacities.

The ARX model exploited on the second part of this project demonstrates that with the extensive use of the sensors' data, a very precise estimation of the heat pump output temperatures can be obtained. This work in progress aims to determine the most optimal control strategy for the functioning of the heat pumps, and eventually for the totality of the energetic systems.

The third part of this project involves the global modeling of all the energetic systems present in ADREAM through the implementation of their physical equations on MatLab and Simulink. Figure 10 provides an overview of the heat pump modeling (in progress) with all its main components which include the governing physical equations.

Even though ADREAM was designed and built on the basis of an optimized energy management, the pursuit of an energy optimization strategy should always be privileged. Currently, the replacement of the constant-flow circulation pumps to variableflow ones is taking place. At the same time, new simulations
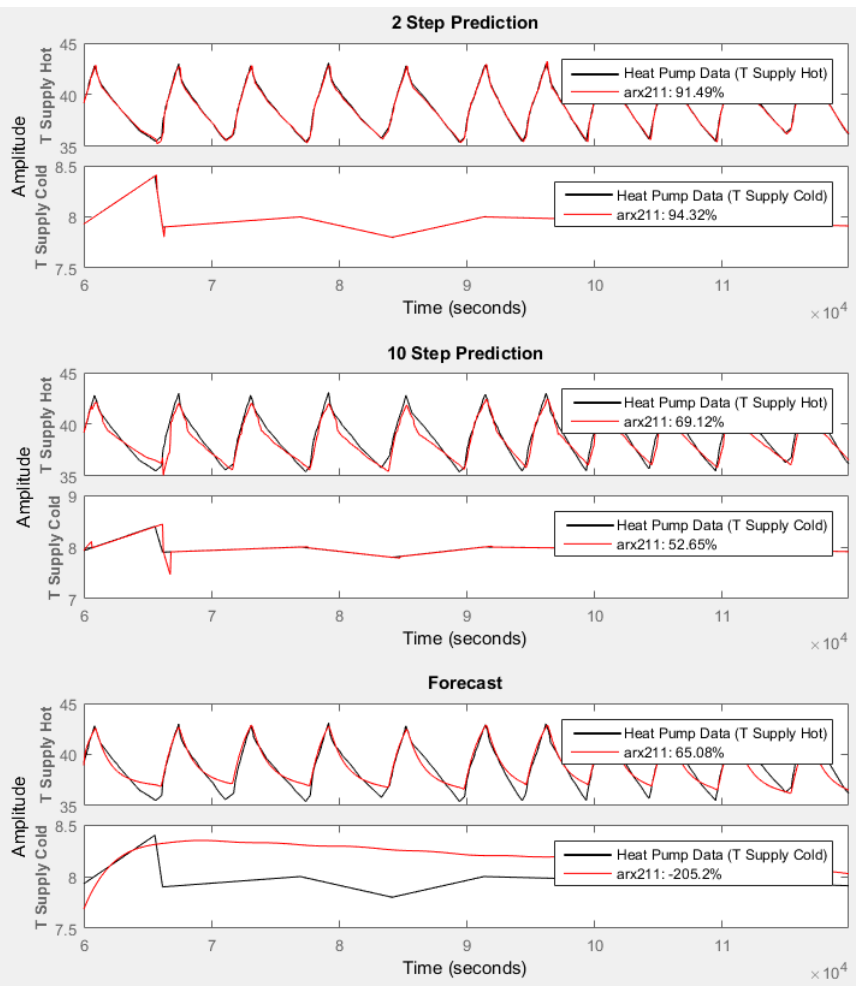

involving the modeling of the heat pumps and the AHUs will be pursued for a more detailed study and analysis of their functioning according to ADREAM's needs. Taking into account this initial modeling of the building at its current state, the upcoming studies and simulations will be performed for the purpose of energy optimization through improvements on the regulation of the heating, cooling and control systems. This project indicates that a district composed by sustainable buildings like ADREAM can promote and sufficiently support the development of a Smart City. 


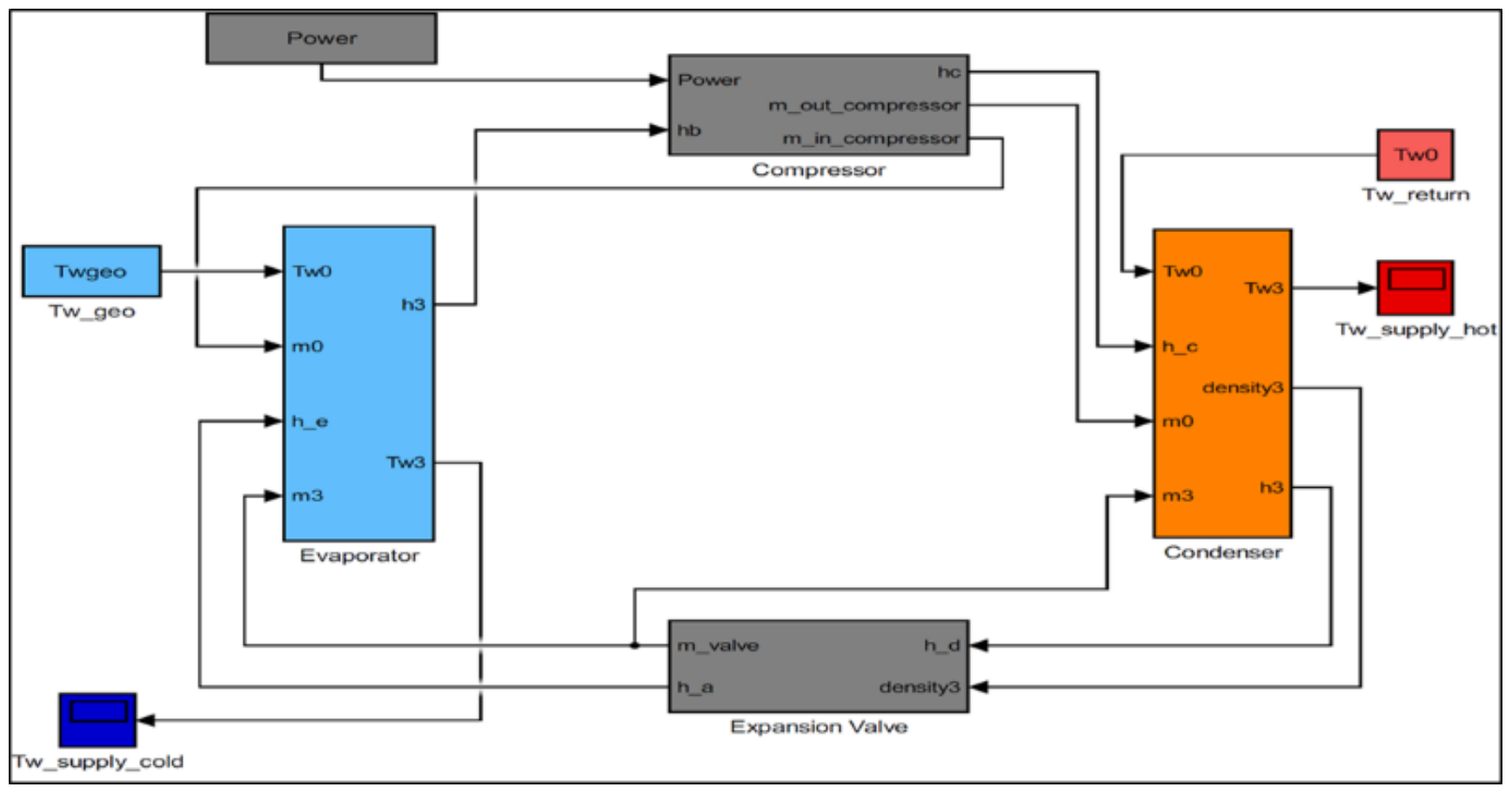

Figure 10: Heat pump modeling in Simulink

VI. References

[1] Izuba Energies, Pleiades+Comfie, <http://www.izuba.fr/logiciel/comfie>.

[2] B. Peuportier, Bancs d'essais de logiciels de simulation thermique, Journée Thématique SFT-IBPSA (2005).

[3] S. Gaaloul, B. Delinchant, F. Wurtz, S. Thiers, B. Peuportier, Couplage d'un modèle thermique issu de COMFIE avec un chauffage régulé électriquement pour une simulation temporelle hybride à pas variable, IBPSA France (2010).

[4] T. Salomon, R. Mikolasek, B. Peuportier, Outil de simulation thermique du bâtiment, COMFIE, Journée Thématique SFTIBPSA (2005).

[5] S. Saidane, L. Gharbi, N. Ghrab-Morcos, Modèle modal de simulation du comportement thermique des bâtiments. Confrontation avec TRNSYS, IBPSA France (2008)

[6] A. Kusiak, M. Li, F. Tang, Modeling and optimization of HVAC energy consumption, Applied Energy 87 (2010) 30923102

[7] ASHRAE, ASHRAE Guideline 14-2002, Measurement of Energy and Demand Savings, ASHRAE, Atlanta, 2002.

[8] A.T. Nguyen, S. Reiter, An investigation on thermal performance of a low cost apartment in hot humid climate of Danang, Energy and Buildings 47 (2012) 237-246

[9] A. Cacabelos, P. Eguia, J.L. Miguez, E. Granada, Calibrated simulation of a public library HVAC system with a ground- source heat pump and a radiant floor using TRNSYS and GenOpt.

[10] H. Boyer, J.P. Chabriat, B. Grondin-Perez, C. Tourrand, J. Brau, Thermal building simulation and computer generation of nodal models. Building and Environment $31-3$ (1996) 207-214.

[11] P. Raftery, M. Keane, A. Costa, Calibration of a detailed simulation model to energy monitoring system data: A methodology and case study, $11^{\text {th }}$ International IBPSA Conference (2009) 1199-1206.

[12] Y. Pan, Z. Huang, G. Wu, Calibrated building energy simulation and its application in a high-rise commercial building in Shanghai, Energy and Buildings 39 (2007) 651-657.

[13] Th-CE 2005, V7.3 (2006).

[14] System Identification Toolbox - ARX Models. <http://www.rohan.sdsu.edu/doc/matlab/toolbox/ident/ch2gui2 0.html $>$.

[15] PCVue Solutions, 〈http://www.pc vuesolutions.com>.

[16] A. Molderink, V. Bakker, M. G. C. Bosman, J. L. Hurink and G. J. M. Smit, Management and Control of Domestic Smart Grid Technology, IEEE Transactions on Smart Grid, vol. 1, no. 2 (2010) 109-119. 